\title{
Research and Analysis of Ecological Environment Quality in the Middle Reaches of the Yangtze River Basin between 2000 and 2019
}

\author{
Shengqing Zhang ${ }^{1}$, Peng Yang ${ }^{1, *}$, Jun Xia ${ }^{2}$, Kunlun Qi ${ }^{1} \mathbb{D}$, Wenyu Wang ${ }^{1}$, Wei Cai ${ }^{1}$ and Nengcheng Chen ${ }^{3} \mathbb{D}$ \\ 1 School of Geography and Information Engineering, China University of Geosciences, Wuhan 430074, China; \\ zhangshengqing@cug.edu.cn (S.Z.); qikunlun@cug.edu.cn (K.Q.); wenyuwanggg@cug.edu.cn (W.W.); \\ cqh770180404@cug.edu.cn (W.C.) \\ 2 State Key Laboratory of Water Resources and Hydropower Engineering Science, Wuhan University, \\ Wuhan 430000, China; xiaj@igsnrr.ac.cn \\ 3 National Engineering Research Center for Geographic Information System, China University of Geosciences, \\ Wuhan 430074, China; cnc@whu.edu.cn \\ * Correspondence: yangp@cug.edu.cn
}

Citation: Zhang, S.; Yang, P.; Xia, J.; Qi, K.; Wang, W.; Cai, W.; Chen, N. Research and Analysis of Ecological Environment Quality in the Middle Reaches of the Yangtze River Basin between 2000 and 2019. Remote Sens. 2021, 13, 4475. https://doi.org/ $10.3390 / \mathrm{rs} 13214475$

Academic Editor: Salman Qureshi

Received: 2 October 2021

Accepted: 27 October 2021

Published: 8 November 2021

Publisher's Note: MDPI stays neutral with regard to jurisdictional claims in published maps and institutional affiliations.

Copyright: (c) 2021 by the authors. Licensee MDPI, Basel, Switzerland. This article is an open access article distributed under the terms and conditions of the Creative Commons Attribution (CC BY) license (https:// creativecommons.org/licenses/by/ $4.0 /)$.

\begin{abstract}
Ecological environment quality is a long-term continuous concept that is affected by various environmental factors. Its assessment has important implications for implementing the planning and protection of dynamic regional ecosystems. Therefore, this study attempted to obtain these indicators (green, dry, wet, heat) through the Google Earth Engine (GEE) platform, and then coupled the ecological environment quality index in the middle reaches of the Yangtze River Basin (MYRB) between 2000 and 2019, based on the remote sensing ecological index (RSEI). The major results show that: (1) changes in the four indicators in summer were more obvious than those in winter, and the changes were concentrated in the central and northern regions of the MYRB; (2) both the modified normalized difference water index (MNDWI) and normalized differential build-up and bare soil index (NDBI) in summer and winter have higher weighting ratios, implying that water body changes and human activities had a greater impact on the ecological environment; and (3) ecological environment quality in the MYRB between 2000 and 2019 was relatively flat. The ecological conditions began to deteriorate in 2008, and substantial ecological degradation was noted in some areas between 2008 and 2019 (18.7\% in the central region, 16.0\% in the eastern region). The MYRB has an important position in the Yangtze River economic belt and is an important part of the Yangtze River protection. This research could provide a theoretical basis and decision support for the development and protection of the Yangtze River Basin (YRB) green economy.
\end{abstract}

Keywords: RSEI; remote sensing; entropy method; ecosystem; space changes

\section{Introduction}

With rapid industrial development and urban expansion, increasingly intense changes in climate have gradually become an issue of common concern to the international community [1]. Recently, the climate has undergone major changes characterized by global warming [2]. Affected by climate change, extreme weather events (e.g., droughts, floods, rainstorms, and tropical typhoons) have occurred frequently, seriously affecting daily life and economic development [3]. Meanwhile, with urban expansion, droughts, floods, water pollution, and other problems are becoming increasingly serious, as they are also aggravated by climate change [4]. Moreover, both have seriously affected the ecological environment [5]. Ecosystems are the most precious resource, providing the necessary open space for human survival and development [6]. Ecological environment quality is a concept used to measure the level of ecological environment, which expresses the suitability of the ecosystem ecological environmental factors in a specific spatial and temporal range for human survival and social economic development [7]. However, ecological environment 
damage has caused some people to experience severe living environments [8]. For instance, due to the occurrence of terrestrial disasters, $42 \%$ of potable water systems in China have been polluted, resulting in $36 \%$ of urban river water becoming completely unusable and causing tremendous damage to the human living environment [9]. Meanwhile, severe resource constraints and sustained high-intensity industrial, traffic, and domestic pollution have reduced the green living environment, and threatened the safety of life and property, as well as the sustainable development of society and the economy [6].

Recently, the development of remote sensing technology has provided substantial data for ecosystem monitoring, and it has also offered reliable instructions for ecological conditions assessment at different scales [10]. Due to the large amount of data, wide coverage, timeliness, and ease of acquisition, remote sensing technology has become an important technical method for studying ecological environments [11]. Various ecological indicators (e.g., forest [12], grassland [13], green space [14], cities [15], and water bodies [16]) have been applied to monitor and evaluate the ecological environment. Previous work has usually applied remote sensing images at medium or low resolution when studying the ecological environment quality $[14,17,18]$. A lower spatial resolution reduces the calculation requirements, it also reduces the precision in small- and medium-area research [19]. Highresolution images can better show the changes in the ecological environment quality when small- and medium-scale regions are studied [20]. Ordinarily, ecosystem dynamics can be extracted by remote sensing images with sufficient spatial and temporal resolution, in which the changes related to appropriate ecological indexes can be quickly and accurately monitored [21].

Single index and low spatial resolution images cannot accurately reflect the actual region situation with complex land types, while multiple indexes and high-resolution images can better reflect the ecological changes, providing rich information support for related research [22]. Therefore, multiple types of ecological environment quality indexes can also be constructed to better understand ecological patterns and processes, and to evaluate regional ecological changes better through the application of remote sensing technology [23]. Subsequently, these multiple indexes can be combined into a final composite index by normalized weights, in which greater weight corresponds to greater contribution [24]. The remote sensing ecological index (RSEI) is a comprehensive index that combines these four indexes of green, dry, wet, and heat [25]. The RSEI can accurately identify the effects of environmental state changes (e.g., plant biomass, plant leaf area, plant coverage, water bodies and wetlands), human activities (e.g., urbanization) [26] and climate change (e.g., temperature) [27] on the quality of the ecosystem. Currently, there are many different methods for calculating weights, which can be roughly divided into two categories: subjective and objective weighting methods [28]. When previous researchers have studied regional environmental quality, they have often used principal component analysis to determine weight factors [25]. In principal component analysis, a high cumulative contribution rate, reasonable practical background, and principal component significance must be ensured [29]. However, the interpretation of principal components in actual situations is generally somewhat vague, leading to uncertainty in the results [30]. Although the principal component analysis is often applied in the classic RSEI model, it cannot avoid the influence of subjective judgment on the results [25]. However, the entropy weight method can effectively avoid the influence [31].

The complex types of land cover and terrain in the middle reaches of the Yangtze River Basin (MYRB) have outstanding regional advantages, excellent natural endowments, and strong comprehensive economic strength [32]. However, the rapid development of cities, complex changes in water bodies and climate change have seriously threatened the ecological environment in the MYRB [33]. To implement effective protection of the Yangtze River Basin (YRB), the Yangtze River Protection Law was passed and reviewed on 26 December 2020, and implemented on 1 March 2021 [34]. The MYRB has become the focus of contemporary ecological environmental research [35]. RSEI has been used to assess the ecological quality of the Erhai [36], Fuzhou [25] and others, but less frequently 
used for ecological quality assessment of the MYRB. Therefore, it is necessary quantitative assessment and analysis on the ecological quality of MYRB under urbanization and climate change.

Therefore, on the above basis, this research focuses the following: (1) analysing the changes in the main environmental factors (the normalized difference vegetation index (NDVI), normalized differential build-up and bare soil index (NDBI), modified normalized difference water index (MNDWI), and land surface temperature index (LST)) in the MYRB based on Landsat satellite data; (2) constructing an ecological environment quality index based on the RESI model and entropy weight method; and (3) evaluating the ecological environment quality and exploring the seasonal pattern of ecological quality in the MYRB. This study uses RSEI and Google Earth Engine (GEE) platform to conduct rapid and efficient ecological quality assessment in the MYRB and explore its change pattern, so as to provide some theoretical basis and decision support for achieving the balance of economic development and ecological protection.

\section{Study Area}

It is characterized by a typical subtropical monsoon climate, with the coldest and hottest temperatures in January and July, respectively [24]. It includes the Hanjiang River Basin (HRB), the Dongting Lake Rivers Basin (DLRB), and various plains, hills, and mountains [37] (Figure 1). It is in the southern part of central China, spanning the three provinces of Hubei, Hunan, and Jiangxi, with $927 \mathrm{~km}$ and $679,000 \mathrm{~km}^{2}$, accounting, respectively, for $14.7 \%$ of the total YRB length and $37.6 \%$ of the entire area [38]. Various urban agglomerations have formed new growth points for economic development in China [39]. That area includes city clusters, in which the ecological environment is notably affected by humans [33].

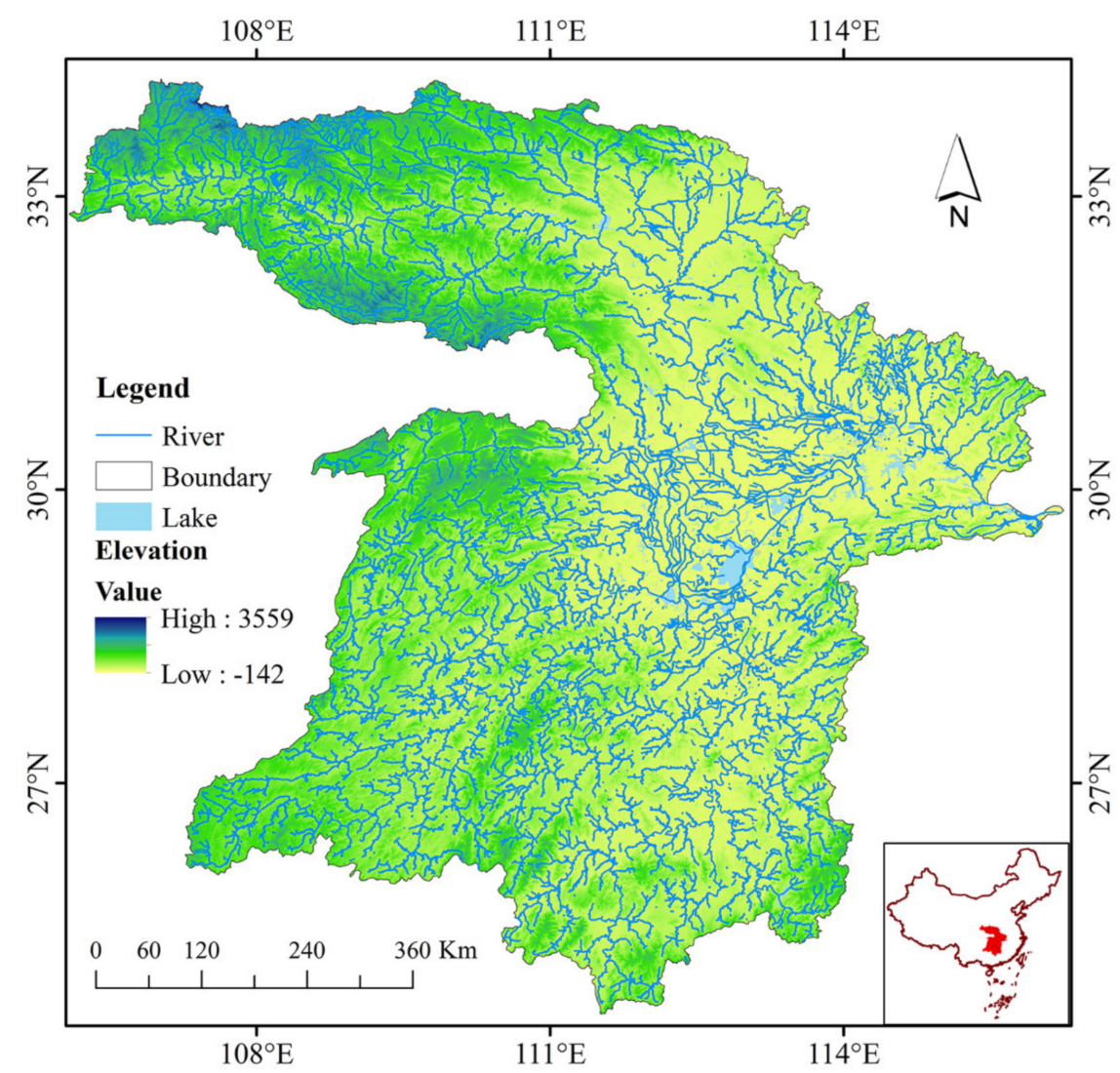

Figure 1. Study area map. 


\section{Materials and Methods}

\subsection{Data and Preconditioning}

Because of the complexity of land cover types in the MYRB, high resolution Landsat remote sensing images $(30 \mathrm{~m})$ were used in this study. This study used the U.S. Geological Survey's Landsat 5, 7, and 8 surface reflectance images (https://earthdata.nasa.gov/, accessed on 10 October 2021). The specific number of satellite images used for each image synthesis and the use of remote sensing images are shown in Tables 1 and 2.

Table 1. Introduction to summer data of ecological environment quality assessment in the MYRB.

\begin{tabular}{ccccccc}
\hline Satellite & $\mathbf{2 0 0 0}$ & $\mathbf{2 0 0 2}$ & $\mathbf{2 0 0 6}$ & $\mathbf{2 0 0 8}$ & $\mathbf{2 0 1 3}$ & $\mathbf{2 0 1 9}$ \\
\hline Landsat 5 & 140 & 135 & 167 & 133 & & \\
Landsat 7 & 159 & 159 & 129 & 130 & 115 & 127 \\
Landsat 8 & & & & & 197 & 190 \\
\hline
\end{tabular}

Table 2. Introduction to winter data of ecological environment quality assessment in the MYRB.

\begin{tabular}{ccccccc}
\hline Satellite & $\mathbf{2 0 0 0}$ & $\mathbf{2 0 0 2}$ & $\mathbf{2 0 0 6}$ & $\mathbf{2 0 0 8}$ & $\mathbf{2 0 1 3}$ & $\mathbf{2 0 1 9}$ \\
\hline Landsat 5 & 105 & 85 & 154 & 142 & & \\
Landsat 7 & 133 & 138 & 148 & 141 & 141 & 127 \\
Landsat 8 & & & & & 182 & 137 \\
\hline
\end{tabular}

The better-quality image data of the Landsat 5 and 8 satellites occur in different time periods, and the image coverage is small, while the Landsat 7 satellite data have a long time-span, but the image quality is poor. Therefore, a single satellite cannot obtain a complete image covering the entire study area within three months. Thus, the Google Earth Engine (GEE) cloud computing platform was used to obtain the Landsat 5 and 7 data from March to May and December to February in the following year. The data for 2000, 2002, 2006, and 2008 were selected for similar and uniform time spans. The average value from March to May each year was calculated and then the remote sensing images of the two satellites were combined to obtain a relatively complete image. The same method was used to synthesize and resample Landsat 7 and 8 data. Due to the lack of remote sensing images, only the data for 2013 and 2019 were obtained under the premise of ensuring the time span and image quality.

\subsection{Methods}

\subsubsection{Normalized Vegetation Index}

NDVI is calculated from the near infra-red and red bands of the light spectrum [40] as shown in Equation (1), with a value between -1 and 1 .

$$
\mathrm{NDVI}=\frac{\rho_{\text {NIR }}-\rho_{\text {Red }}}{\rho_{\text {NIR }}+\rho_{\text {Red }}}
$$

where $\rho_{N I R}$ and $\rho_{R}$ are the near infra-red and red band reflectances.

\subsubsection{Normalized Building Index}

NDBI is a composite of the urban building index (BI) and the bare soil index (BSI) [41], and is a negative indicator, which is written as follows:

$$
\begin{gathered}
\mathrm{BSI}=\frac{\left(\rho_{\text {SWIR } 1}+\rho_{\text {Red }}\right)-\left(\rho_{\text {NIR }}+\rho_{\text {Blue }}\right)}{\left(\rho_{\text {SWIR } 1}+\rho_{\text {Red }}\right)+\left(\rho_{\text {NIR }}+\rho_{\text {Blue }}\right)} \\
\mathrm{BI}=\frac{\frac{2 \rho_{\text {SWIR } 1}}{\rho_{\text {SWIR1 }}+\rho_{\text {NIR }}}-\left(\frac{\rho_{\text {NIR }}}{\rho_{\text {NIR }}+\rho_{\text {Red }}}+\frac{\rho_{\text {Green }}}{\rho_{\text {Green }}+\rho_{\text {RSWIR1 } 1}}\right)}{\frac{2 \rho_{\text {SWIR } 1}}{\rho_{S W I R 1}+\rho_{\text {NIR }}}+\left(\frac{\rho_{\text {NIR }}}{\rho_{\text {NIR }}+\rho_{\text {Red }}}+\frac{\rho_{\text {Green }}}{\rho_{\text {Green }}+\rho_{\text {RSWIR1 } 1}}\right)}
\end{gathered}
$$


where $\rho_{\text {Blue }}, \rho_{\text {Green }}, \rho_{\text {Red }}, \rho_{N I R}$, and $\rho_{R S W I R 1}$ are the reflectances of blue, green, red, near infra-red, and short infra-red band 1 , respectively.

\subsubsection{Modified Normalized Difference Water Index}

The MNDWI is calculated from the green band and mid infra-red band [16]. The calculation is given by Equation (4).

$$
\mathrm{MNDWI}=\frac{\rho_{\text {Green }}-\rho_{\text {MIR }}}{\rho_{\text {Green }}+\rho_{\text {MIR }}}
$$

where $\rho_{M I R}$ is the reflectance of the mid infra-red band.

\subsubsection{Land Surface Temperature Index}

LST was obtained through atmospheric correction using remote sensing images [42]. First, the influence of the atmosphere on the surface thermal radiation is estimated, and this fraction of the atmospheric influence is subtracted from the total thermal radiation observed by the satellite sensor, so that the surface thermal radiation intensity is obtained. Then, this thermal radiation intensity is converted into the corresponding surface temperature. The calculation formula is as follows:

$$
\begin{gathered}
L_{\lambda}=\left[\varepsilon B\left(T_{S}\right)+(1-\varepsilon) L \downarrow\right] \tau+L \uparrow \\
B\left(T_{S}\right)=\left[L_{\lambda}-L \uparrow-\tau(1-\varepsilon) L \downarrow\right] / \tau \varepsilon \\
T_{S}=K_{2} / \ln \left(K_{1} / B\left(T_{S}\right)+1\right)
\end{gathered}
$$

where $\varepsilon$ is the land surface emissivity (LSE), $T_{S}$ is the real surface temperature, $B\left(T_{S}\right)$ is blackbody thermal radiance, $\tau$ is atmospheric thermal infrared transmittance, $L_{\lambda}$ is thermal infrared radiance, $L \uparrow$ is upward atmospheric radiance, and $L \downarrow$ is downward atmospheric radiance.

Finally, NDVI, NDBI, MNDWI, and LST were obtained from remote sensing images based on the GEE platform and calculation method.

\subsubsection{Remote Sensing Ecological Index}

The RSEI is a comprehensive index that combines these four indexes of green, dry, wet, and heat [25]. NDVI is closely related to plant biomass, plant leaf area, and plant coverage, which can represent greenness. NDBI can indicate the change and destruction of the original natural ecosystem caused by human construction, housing, activities, etc., resulting in passive ground desiccation [26]. Because of the numerous human activities in the MYRB and the abundant building complexes, MNDWI can distinguish the moisture status of water bodies and buildings, including plants, wetlands, and soil, which is closely related to changes in the ecological environment [27]. Therefore, NDVI, NDBI, MNDWI, and LST were used to represent green, dry, wet, and heat, respectively. The calculation formula for the RSEI is as follows:

$$
R S E I=f(N D V I, N D B I, M N D W I, L S T) .
$$

\subsubsection{Weight and Data Standardization}

To ensure result objectivity, the entropy weight method was selected to determine the weight [31]. The entropy method calculates the dataset variance, for which the greater the degree of similarity, the smaller the contribution to the final ecological situation. This is consistent with the research objective, indicating that the smaller the degree of variation in the time series, the smaller the amount of information reflected, and the lower the 
corresponding weight. Notably, the index must be normalized before obtaining the weights using the entropy method, according to the following two methods:

$$
\begin{aligned}
& X_{P}=\frac{X_{i}-X_{\min }}{X_{\max }-X_{\min }} \\
& X_{n}=\frac{X_{\max }-X_{i}}{X_{\max }-X_{\min }}
\end{aligned}
$$

where $X_{P}$ indicates a positive effect on the result and $X_{n}$ indicates a negative effect on the result. $X_{i}, X_{\max }$, and $X_{\min }$ represent the data, maximum, and minimum values, respectively.

\subsubsection{Sen's Slope Estimation}

Sen's slope estimation method can calculate the slope of the time series and the significance level of the $\mathrm{z}$ value [43]. The slope $m$ represents the average rate of change in the data sequence. The calculation formula for the slope $m$ is shown in Equation (11). When $m>0$, the sequence is increasing; when $m<0$ the sequence is decreasing; and when $m=0$, no trend is apparent. The significance level $\mathrm{z}$ value indicates a significant change in the element value. When $z>0$, there is an increasing trend, and when $z>1.96$, it indicates a significant increase; when $\mathrm{z}<0$, it indicates a decreasing trend, and less than -1.96 indicates a significant decrease. This study analyses ecological changes in a continuous time series. Using Sen's slope estimation method, the changes and trends in the study area can be visualized.

$$
m=\operatorname{Median}\left(\frac{x_{j}-x_{i}}{j-i}\right), \forall \mathrm{j}>\mathrm{I}
$$

where $m$ indicates slope, Median is the median function, and $x_{t}=\left(x_{1}, x_{2}, x_{3}, \cdots, x_{n}\right)$ represents the time series.

\subsubsection{Calculating the RSEI in the MYRB}

According to the above-mentioned data pre-processing and weight calculation methods, four indicators (NDVI, NDBI, MNDWI, and LST) in the MYRB can be obtained for fitting the RSEI, which can be roughly divided into the following steps.

First, NDVI, MNDWI, and LST are normalized according to Equation (9); NDBI is a negative indicator, thus NDBI is normalized according to Equation (10). Second, after the normalized pixel values are obtained, six years of data from 2000 to 2019 are weighted according to the values in the four pixels corresponding to the latitude and longitude coordinates of the corresponding points.

Table 3 shows the coordinates of pixels for different indices. The data matrix of coordinate points is listed in a time series. After obtaining the data matrix, the proportion of each element in the column according to the data matrix is calculated to obtain the probability matrix, and each element must be calculated using the following formula:

$$
p_{i j}=\frac{\widetilde{z}_{i j}}{\sum_{i=1}^{n} \widetilde{z}_{i j}}
$$

where $p_{i j}$ is the element in the probability matrix $P$ and $\widetilde{z}_{i j}$ is the standardized index.

Then, the information entropy $e$ of each indicator is calculated according to the probability matrix $P$ as follows:

$$
e_{j}=-\frac{1}{\ln n} \sum_{i=1}^{n} p_{i j} \ln \left(p_{i j}\right)(j=1,2,3, \cdots, m)
$$


where $e_{j}$ is the value of each information entropy point in the information entropy matrix $E$. Finally, the information utility value of each element is calculated, and the information utility value obtained by normalization is the weight of each indicator.

$$
w_{i}=\frac{1-e_{j}}{\operatorname{sum}\left(1-e_{j}\right)}
$$

where $w_{i}$ is the final weight calculated for each indicator; $1-e_{j}$ indicates the information utility value of each element; and after calculating the weight value of each pixel, NDVI, NDBI, MNDWI, and LST are weighted and summed according to the weight, and the RSEI pixel value corresponding to each coordinate is obtained.

Table 3. Coordinate point pixel value matrix.

\begin{tabular}{ccccc}
\hline Time & NDVI & NDBI & MNDWI & LST \\
\hline 2000 & a1 & b1 & c1 & d1 \\
2002 & a2 & b2 & c2 & d2 \\
2006 & a3 & b3 & c3 & d3 \\
2008 & a4 & b4 & c4 & d4 \\
2013 & a5 & b5 & c5 & d5 \\
2019 & a6 & b6 & c6 & d6 \\
\hline
\end{tabular}

\section{Results}

\subsection{Multiple Indices Change in the MYRB during 2000-2019}

Figure 2 shows the changes in the four ecological factors in the summers of 2000, 2002, 2006, 2008, 2013, and 2019 in the MYRB. The results showed that the NDVI of the MYRB was mainly concentrated in the north between 2000 and 2006, showing a downward trend (6.4\% between 2000-2006) (Figure 2(a.1-a.3)). NDVI showed an increasing trend between 2006 and 2019 (14.1\% in the northwest, 10.4\% in the southeast) (Figure 2(a.4-a.6)). NDBI decreased by $25.3 \%$ in the north and increased by $46.4 \%$ in the south between 2000 and 2008 (Figure 2(b.1-b.4)). However, there were significant increases between 2008 and 2019 (21.5\% in the north), indicating that human activities were more frequent recently. MNDWI changed noticeably from 2000 to 2019 (Figure 2(c.1-c.6)), and MNDWI increased by an average of $32.5 \%$ in the central and northern regions between 2000 and 2008 and decreased by $39.3 \%$ in the north during 2008 and 2019. The overall distribution of LST showed little change and was mainly concentrated in the northeast between 2000 and 2019, there were significant increases between 2008 and 2019 (38.7\% in the southwest).

Figure 3 shows the distribution map of the four types of indices in winter. The indexes in winter were lower, and the overall trend in winter was lower without obvious changes compared with summer. In winter, NDVI decreased by $25.3 \%$ from 2000 to 2008 (Figure 3(a.1-a.4)). However, NDVI increased by 24.9\% compared with that in 2019. NDBI increased overall with the change in year, increasing by an average of $1.1 \%$ and decreased by $5.1 \%$ between 2000 and 2006, and 2006 and 2019, respectively, concentrated in the northeast region, and the growth was generally consistent with that in summer. MNDWI was more evenly distributed throughout the region (Figure 3(c.1-c.6)), with an average decrease of $12.9 \%$. Meanwhile, MNDWI was higher in winter than in summer, indicating that MNDWI was seasonally affected. LST gradually changed from higher in the south to more evenly distributed from 2000 to 2019 but was still higher in the northeast and south than other regions. In winter, NDBI and LST had opposite distributions in space, but the spatial distribution of NDBI and LST was consistent in summer, indicating that seasonal changes greatly affect the spatial distribution of surface temperature. 
a.1
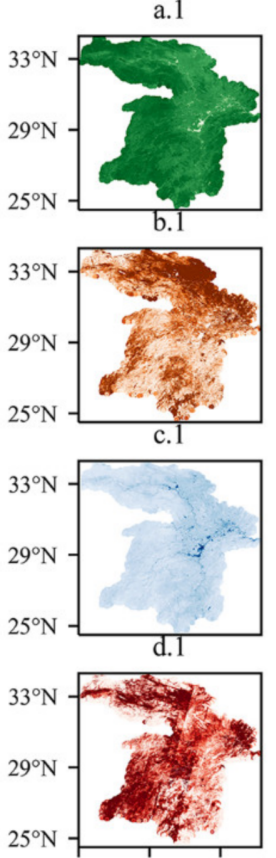

$106^{\circ} \mathrm{E} 110^{\circ} \mathrm{E} 114^{\circ} \mathrm{E} \quad 106^{\circ} \mathrm{E} 110^{\circ} \mathrm{E} 114^{\circ} \mathrm{E}$ a. 2
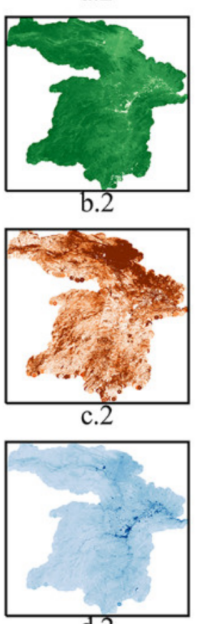

$\mathrm{d} .2$

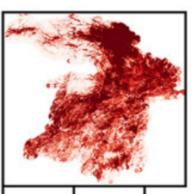

a. 3
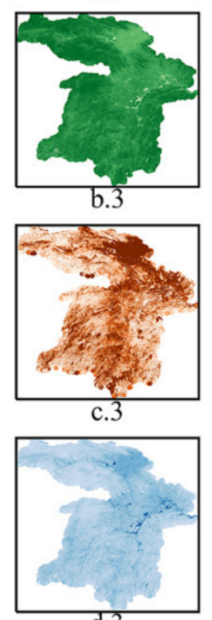

d. 3

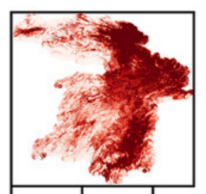

a.4
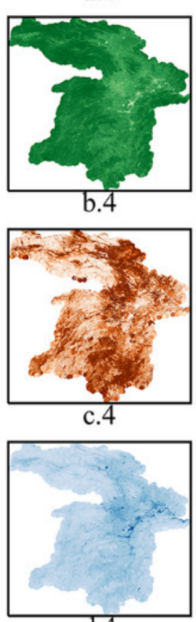

d. 4

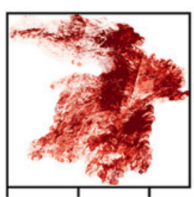

a.5
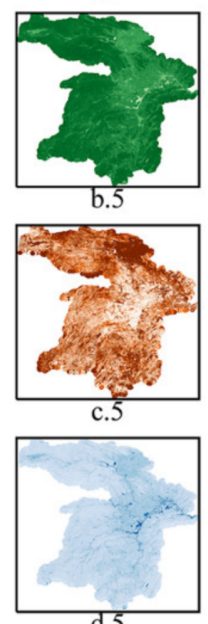

d.5

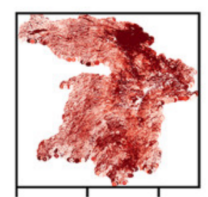

a.6
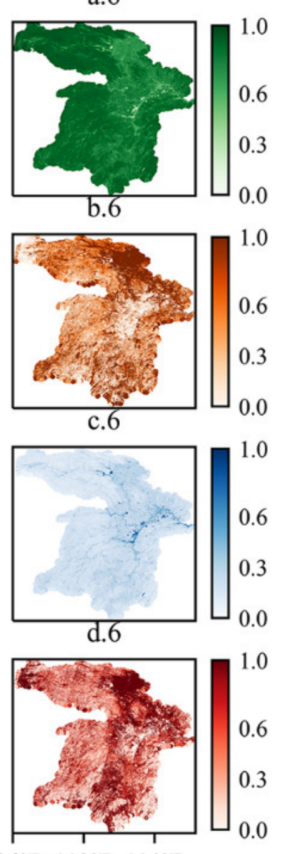

Figure 2. Distribution map of four types of indices in summer.((a.1-a.6), (b.1-b.6), (c.1-c.6), (d.1-d.6) represents the NDVI, NDBI, MNDWI and LST in the six years of 2000, 2002, 2006, 2008, 2013 and 2019, respectively).
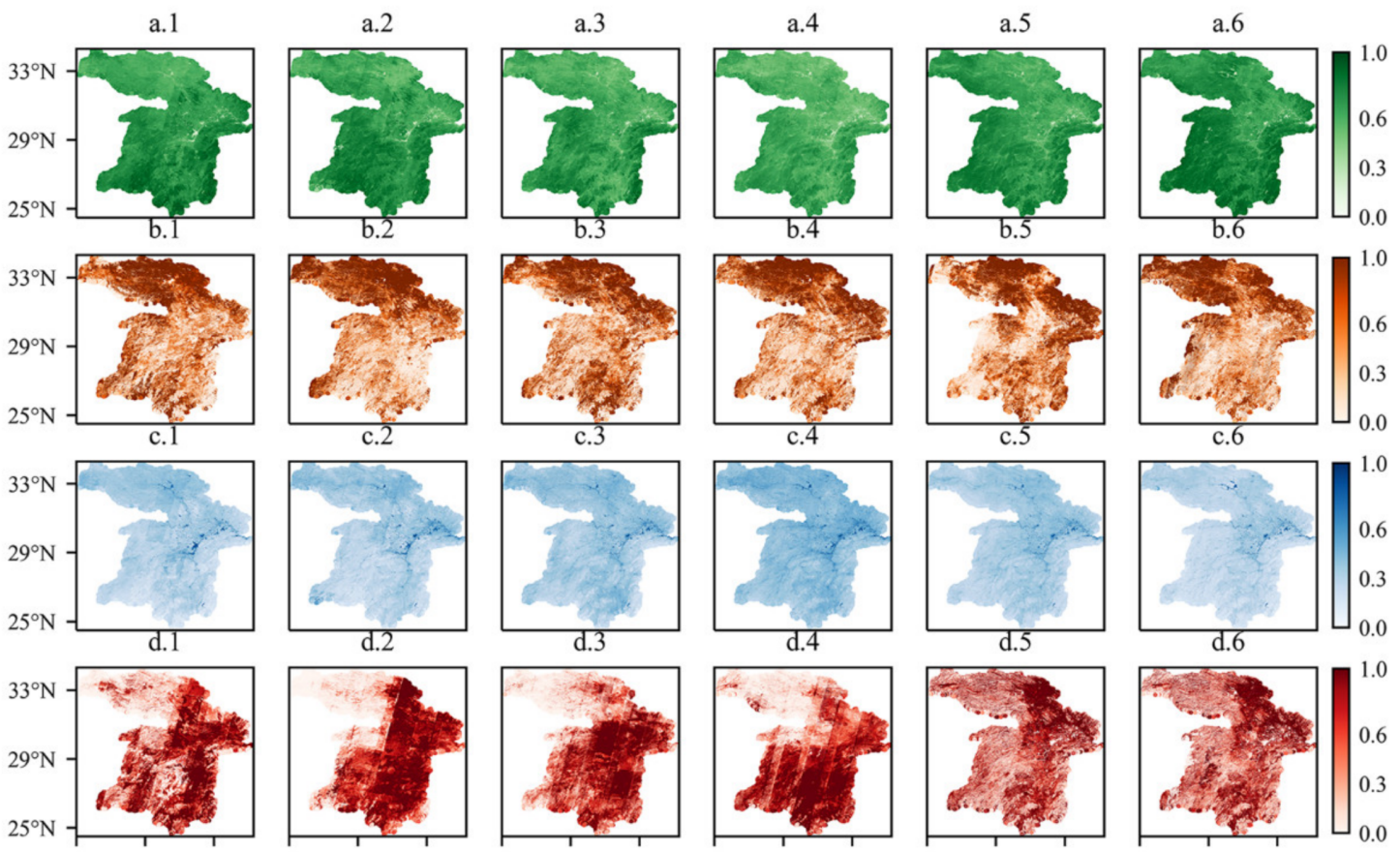

$106^{\circ} \mathrm{E} \quad 110^{\circ} \mathrm{E} \quad 114^{\circ} \mathrm{E} \quad 106^{\circ} \mathrm{E} \quad 110^{\circ} \mathrm{E} \quad 114^{\circ} \mathrm{E} \quad 106^{\circ} \mathrm{E} \quad 110^{\circ} \mathrm{E} \quad 114^{\circ} \mathrm{E} \quad 106^{\circ} \mathrm{E} \quad 110^{\circ} \mathrm{E} \quad 114^{\circ} \mathrm{E} \quad 106^{\circ} \mathrm{E} \quad 110^{\circ} \mathrm{E} \quad 114^{\circ} \mathrm{E} \quad 106^{\circ} \mathrm{E} \quad 110^{\circ} \mathrm{E} \quad 114^{\circ} \mathrm{E}$

Figure 3. Distribution map of four types of indices in winter. ((a.1-a.6), (b.1-b.6), (c.1-c.6), (d.1-d.6) represents the NDVI, NDBI, MNDWI and LST in the six years of 2000, 2002, 2006, 2008, 2013 and 2019, respectively).

\subsection{Multiple Indices Change in the MYRB during 2000-2019}

In order to compare the average weight proportion of different indices more intuitively, this study calculated the average weight within the whole study area according to the weights of different pixel points of remote sensing images. The summer index average weight statistics are presented in Table 4. NDVI in the large region occupied the smallest weight, indicating that NDVI had the smallest contribution to RSEI between 2000 and 2019 
(Figure 4a); the weights of MNDWI were higher than those of NDVI, indicating that water body changes were more obvious than greenness, the impact of water body changes on the ecology was also more serious. The average weight of NDBI was significantly higher than that of NDVI and MNDWI, which meant that the impact of human activities on the ecological environment was greater. Furthermore, the average weight of LST was the highest, indicating that changes in temperature greatly affected the ecological environment. For example, the temperature changed significantly in the south and northeast (Figure 2), which had a substantial impact on the changes in the ecological environment quality in the MYRB.

Table 4. Weight statistics for different indexes in summer.

\begin{tabular}{cccc}
\hline Name & Max & Min & Mean \\
\hline NDVI & 0.8433 & 0 & 0.0143 \\
NDBI & 0.9947 & 0 & 0.4214 \\
MNDWI & 0.9952 & 0 & 0.1245 \\
LST & 0.9978 & 0 & 0.4398 \\
\hline
\end{tabular}
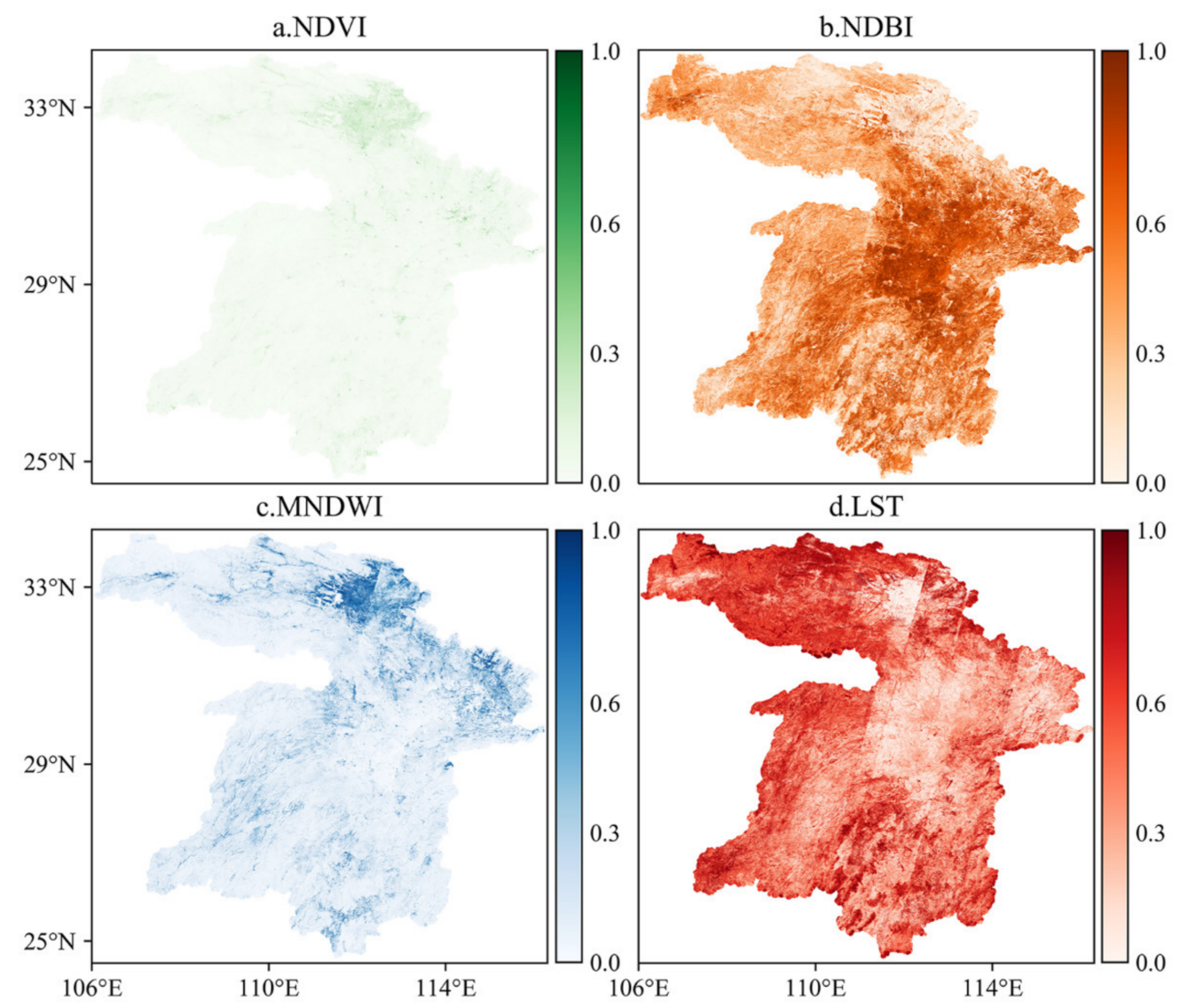

Figure 4. Distribution map of the weights of (a) NDVI, (b) NDBI, (c) MNDWI and (d) LST in the MYRB in summer.

The weight statistics of the four indices in winter are listed in Table 5. The average weights of NDVI and MNDWI showed little change in winter. Compared with summer, the water bodies did not change significantly, MNDWI changed less obviously than in summer (Figure 2(c.1-c.6) and Figure 3(c.1-c.6)), and the proportion of MNDWI average weight decreased. The average weight of LST had the highest average weight, followed by the NDBI. The maximum and minimum values of the four indexes were similar in summer and winter, but the maximum and minimum values of each index had a large gap, indicating that the weight values of each coordinate were not evenly distributed. As the location of the area changed, the weight value also changed substantially. 
Table 5. Weight statistics of different indexes in winter.

\begin{tabular}{cccc}
\hline Name & Max & Min & Mean \\
\hline NDVI & 0.7245 & 0 & 0.0201 \\
NDBI & 0.9981 & 0 & 0.4347 \\
MNDWI & 0.9513 & 0 & 0.0646 \\
LST & 0.9996 & 0 & 0.4506 \\
\hline
\end{tabular}

The weight distribution of each index in summer is shown in Figure 4. The weight of NDVI were higher in the north and east, indicating that the greenness had larger changes in these areas. The weights of NDBI were not uniformly distributed (Figure $4 b$ ). The NDBI weights throughout the region were relatively high; in the central region and northern region, it was slightly higher than the average level, indicating that the MYRB has been extensively affected by human activities in recent years. The weight of MNDWI was higher than NDVI (Figure 4c), and MNDWI with higher weights were mainly distributed in the northeast region, while the south regions had lower weights. The LST weights were more evenly distributed in the region, and northwest and eastern regions, in which the temperature had changed significantly, exhibited higher weights.

The winter indices are shown in Figure 5. The changes in the NDVI and MNDWI weights were not obvious in winter. The decrease in the MNDWI weights was more serious (Figure 5c), indicating that the water body changes in winter were not as significant in summer. This was consistent with the changes in the average MNDWI weight in Tables 4 and 5. The MNDWI weight was more evenly distributed in winter. There were obvious changes in NDBI and LST. NDBI increased significantly in the south region (Figure 5b), and the areas with higher weights moved to the south and central regions. The regions with high LST weights were concentrated in the northern regions (Figure 5d), indicating that seasonal changes also affected the regional transfer of weights. In addition, the spatial distribution of NDBI and LST weights was clearly opposite in summer and winter, suggesting that regions with high human activity did not have significant surface temperature changes, human activities had reduced the intensity of surface temperature changes. This was also consistent with the opposite spatial distribution of NDBI and LST in Figure 3.

\subsection{RSEI Changes in the MYRB during 2000-2019}

The spatial distribution of the RSEI during summer is shown in Figure 6. The RSEI did change significantly in northwest and southeast in 2000-2008, the RSEI decreased $40 \%$ and increased $113.5 \%$ in the northwest and southeast MYRB, respectively (Figure 6); the RSEI decreased $70.4 \%$ in the central and northeast regions in 2008-2019, indicating that the ecological environment in these regions deteriorated more severely. The situation improved significantly in northwest between 2008 and 2019. The RSEI in the northwest regions of the MYRB increased, signifying that the ecological environment of these regions had also improved somewhat. However, the overall situation remained poor, the low ecological quality was mainly concentrated in the central region.

The RSEI distribution during winter is shown in Figure 7. Affected by the monsoon and the difference in ecological conditions between winter and summer, the RSEI spatial distribution in winter and summer also showed significant differences. In winter, the RSEI in most areas did not change significantly and only decreased by an average of $4.2 \%$ from 2000 to 2008 (Figure 7). The RSEI in the north-western MYRB increased and then decreased between 2008 and 2019. In addition, the ecological conditions in most areas changed little in these years, and there were some changes in the ecological conditions in the southwest, but they were not obvious compared with the overall situation. The RSEI improved in a large area during 2008-2019. The entire region showed an increasing trend from the northwest and gradually radiating to the northeast; the northern area had the most significant improvement (62.7\% between 2008 and 2019), and the ecological conditions in the entire region continuously improvement from 2008 to 2019. 


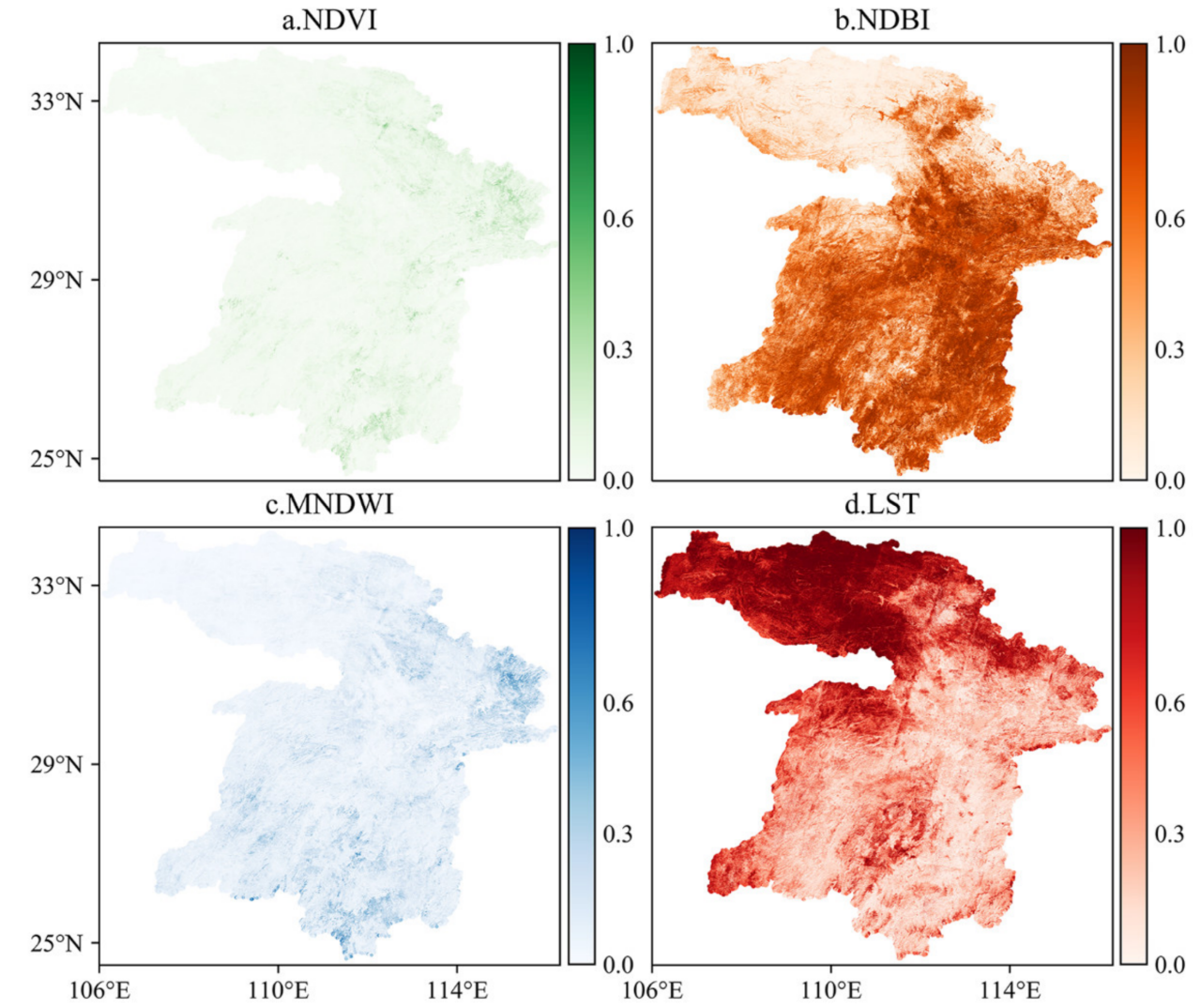

Figure 5. Distribution map of the weight of (a) NDVI, (b) NDBI, (c) MNDWI and (d) LST in the MYRB in winter.
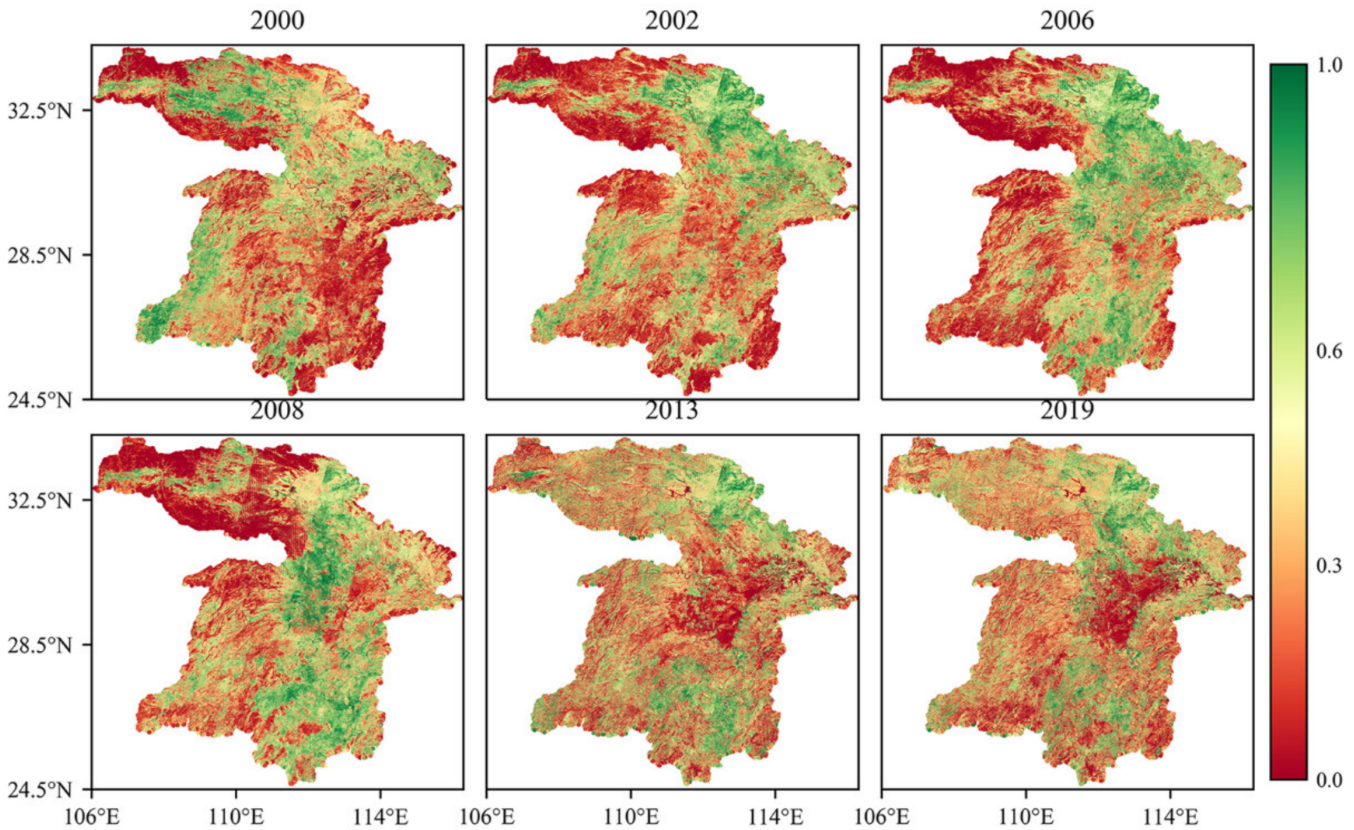

Figure 6. Spatial distribution of RSEI in the MYRB in the summer.

\subsection{Ecological Quality Change Analysis}

The distribution of the slope and significance level eigenvalues for winter and summer are shown in Figure 8. The regional decline was widely distributed throughout the region in summer, and was mainly concentrated in the southwest, east, and north (Figure 8(b.1)). It can be seen that the situation in most declining areas was very significant. The results implied that the ecological environment in the region had deteriorated over a wide range 
and the deterioration in most areas was significant, although a small part of the ecological situation improved between 2000 and 2019. The ecological environment deterioration in winter was smaller than that in summer, and there was less area reaching a significant level than in summer, which was consistent with the RSEI trend in Figure 6; Figure 7. According to Figure 8(b.2), the decline in ecological level in winter was better than that in summer, but the situation in most areas was still not optimistic, and only a few areas achieved significant improvement in ecological conditions.
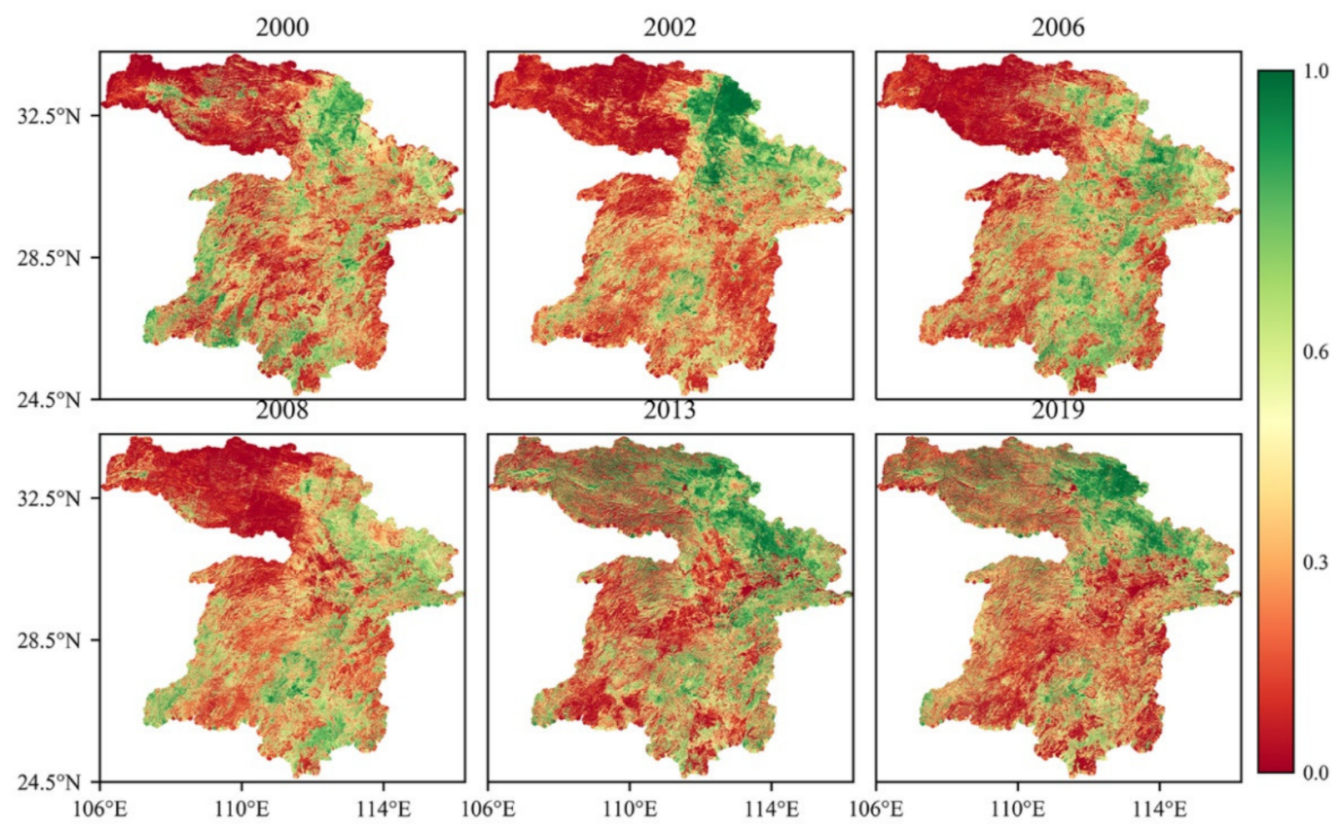

Figure 7. Spatial distribution of the RSEI in the MYRB in the winter.
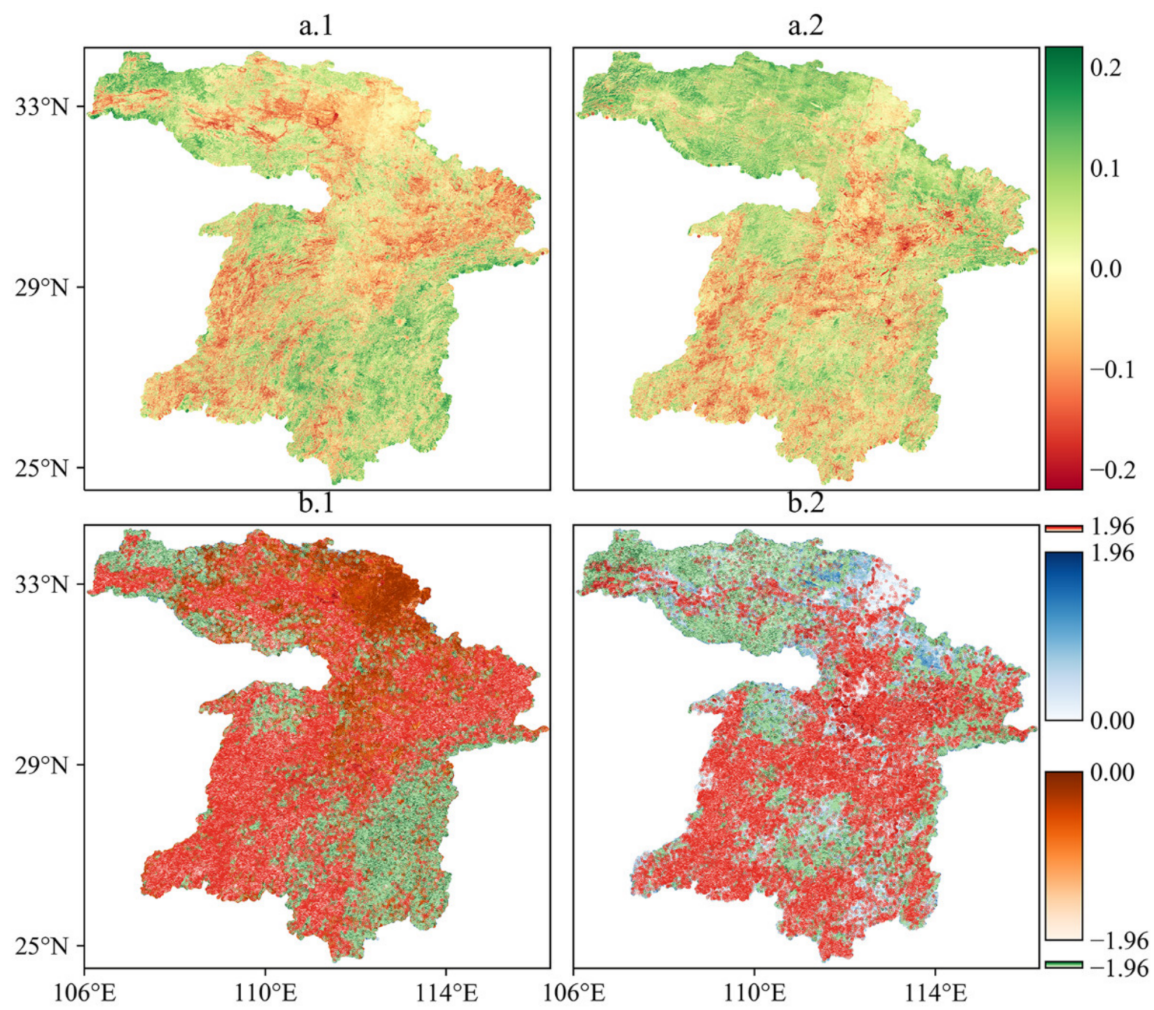

Figure 8. Distribution of eigenvalues of slope and significance level in winter and summer ((a.1,a.2) are the distribution of slope in summer and winter, respectively; (b.1,b.2) are the distribution map of significant level in summer and winter). 


\section{Discussion}

\subsection{Data and Model Advantages}

In this study, the GEE platform was used to synthesize the data using Landsat 5, 7, and 8, and to obtain MYRB images, which were processed and analysed. When other researchers conducted similar research, they mostly used moderate-resolution imaging spectroradiometer (MODIS) remote sensing data to study the research area [31]. MODIS data are easy to obtain and have the advantages of wide coverage and multiple data types. The use of MODIS data could reduce many calculation steps, but for small and medium-sized areas, the spatial resolution of MODIS data is too large, and cannot show the characteristics of changes within the study area well [18]; therefore, this study used Landsat satellite data. It was necessary to filter and synthesize the images because the data coverage was relatively small. The study area was a small- to medium-sized area, and high-resolution images could capture the situation and changes in the region and its complex internal dynamics. This research used the RSEI model framework, which was based on remote sensing data and the greenness, dryness, wetness, and heat factors in the study area to construct an RSEI model that expresses the regional ecological quality [29]. Although humidity was calculated by tasseling cap transformation in the original RSEI model [36], MNDWI was used to represent wet in RSEI for the large number of water body and wetland types in the MYRB. The RSEI can quickly assess the long-term ecological quality of a region and determine changes by comparing the ecological quality of different years, which yields a more dynamic and intuitive ecological quality understanding in the MYRB [44]. The index was extracted from remote sensing data, and was easy to obtain, convenient to visualize, fast, efficient, and intuitive.

\subsection{Weight Method and Result Verification}

For the same experiment, different weighting methods greatly affected the study results. At present, the commonly used weighting methods can be divided into two types. One method is the subjective weighting method, which is substantially influenced by decision makers and reference standards, such as the Delphi method [45] and the Analytic Hierarchy Process (AHP) method [46]. The other is the objective weight method that uses a certain calculation method adopted by the decision matrix to obtain the weight (e.g., the deviation maximization method [47] and the coefficient of variation method [48]). The subjective weight method is easily affected by subjective factors, and the ecological quality of a specific area is a relatively objective concept. Therefore, this study chose the objective entropy weight method to weigh the remote sensing factors. The assignment of the entropy method was only related to the relationship among the values themselves [49], and the weights were obtained by numerical calculations. The four factors were also calculated from the existing real-time remote sensing images. Their combination ensured the objective reality of the results.

The different impact factors are strongly influenced by seasonal changes, the contribution of different impact factors to the ecological environment varies by season. There was a large difference in the type of vegetation growth and vegetation ecological water storage between summer and winter [50], this led to the fact that NDVI also varies within the region in different seasons. The country's rapid economic development, industrial development, and urban expansion all affected the quality of the original ecological environment between 2000 and 2019 [51]. With the rapid development of the Yangtze River Economic Zone and the advancement of urbanization [52], the increasing intensity of human activity has had a negative impact on the ecological environment in the MYRB [53], the temperature has also risen between 2000 and 2019 [43], greatly affecting the ecological quality of the MYRB. The ecological environment quality was severely affected by human activities and temperature change according to higher average weighting of NDBI and LST in both summer (Table 4) and winter (Table 5) in the MYRB.

The ecological quality reduced significantly between 2000 and 2008. Li et al. (2007, 2009) $[54,55]$ reported the ecological quality in HRB was excellent in 2006, but moderate 
pollution in 2008. With the continuous development of the Yangtze River Economic Belt, the green development of the MYRB has gradually become more and more effective during the period 2008-2012, and the area of some urbanized green areas has increased, prompting a slow improvement in the quality of their regional ecological environment between 2010 and 2012 [52]. Meanwhile, the ecological quality improved slightly in the period 2013-2019, although the overall situation was still one of continuous deterioration [56]. Both the water quality in the major lakes and reservoirs in Hubei Province and Hunan Province has become moderately polluted in 2020 [57,58]. Because of the increasingly severe environmental problems in the MYRB, the Ministry of Water Resources drafted the Yangtze River Protection Law in July 2018 which was implemented on 1 March 2021, and showed that the decline in environmental quality in the YRB had attracted national attention and verified the research results [34].

\subsection{Shortcomings of This Research and Suggestions for Improvement}

Due to the data and time-span limitations of the Landsat 5, 7, and 8 satellites, the remote sensing images used in this study were synthesized and extracted; however, they were not sufficient to completely replace the remote sensing images at the same time point, which introduced some errors. Moreover, the ecological environment is complex, with complicated internal conditions. The four indicators selected in the RSEI model could not fully represent the real situation of the complex ecological environment, which could only be expressed approximately. This research uses the objective entropy method as the weighting method, which avoids the interference caused by subjective factors and provides an intuitive expression of numerical calculation. The results were highly authentic, but the number of calculations was excessive, and the calculations were time-consuming. In future work, using better quality and more complete data (e.g., Worldview, Pleiades-1, Gaofen-2 and other high-resolution satellite products), and finding ways to reduce the calculation load will be paramount. This will enable using remote sensing images to obtain better results for future ecological quality evaluations.

\section{Conclusions}

This study used Landsat satellite remote sensing data to establish the RSEI evaluation model of the MYRB area. Subsequently, the entropy weight method was used to determine the factor weights, and the ecological and index change of the MYRB region were analysed with the following findings.

(1) The index changes mainly started between 2008 and 2013. The changes in NDBI and LST were more obvious than those in NDVI and LST and were more obvious in summer than winter. The changes in winter and summer were concentrated in the central, northwest and northern regions of MYRB;

(2) Due to the monsoon influence, the weight of summer and winter was different. However, the weights of LST and NDBI are higher than those in NDVI and MNDWI in different seasons. Increasing human activity caused deterioration of the ecological environment. Temperature increased greatly and had the most serious impact on the regional ecological quality;

(3) The overall ecological quality was poor in the MYRB. The ecological change in summer and winter was generally the same. The ecological quality trend declined suddenly in the period 2000-2008. The overall ecological quality in winter was better than that in summer because of the monsoon climate. The ecological quality was improved in summer and winter between 2008 and 2019. This study revealed the ecological impact of seasonal changes and changes in human and natural conditions, indicating that people were focusing on regional green development along with economic development, which was one of the important conditions for maintaining a good relationship between humans and the ecological environment. It also provided a theoretical basis and decision support for the harmonious coexistence between human beings and nature. 
Author Contributions: Conceptualization, S.Z. and P.Y.; methodology, P.Y.; software, S.Z.; validation, W.C.; formal analysis, K.Q.; investigation, W.W.; resources, J.X.; data curation, N.C.; writing—original draft preparation, S.Z.; writing-review and editing, S.Z. and P.Y.; funding acquisition, P.Y. All authors have read and agreed to the published version of the manuscript.

Funding: This research was funded by Visiting Researcher Fund Program of State Key Laboratory of Water Resources and Hydropower Engineering Science (grant No. 2020SWG01) and Youth Fund for Humanities and Social Science Research of the Ministry of Education (grant No. 20YJCZH207).

Data Availability Statement: Remote sensing image data were derived from https:/ / developers. google.com/earth-engine/datasets/catalog/landsat (accessed on 10 October 2021). We would like to express our sincere thanks to all data supporters and websites.

Conflicts of Interest: The authors declare no conflict of interest.

\section{References}

1. Li, Y.; Liu, Y.; Ye, W.; Xu, L.; Zhu, G.; Zhang, X.; Zhang, C. A new assessment of modern climate change, China-An approach based on paleo-climate. Earth-Sci. Rev. 2018, 177, 458-477. [CrossRef]

2. He, Y.; Theakstone, W.H.; Zhang, Z.L.; Zhang, D.A.; Yao, T.D.; Chen, T. Asynchronous Holocene climatic change across China. Quat. Res. 2004, 61, 52-63. [CrossRef]

3. Khoi, D.N.; Trang, H.T. Analysis of Changes in Precipitation and Extremes Events in Ho Chi Minh City, Vietnam. Proc. Eng. 2016, 142, 229-235. [CrossRef]

4. Liang, C.; Li, D.; Yuan, Z.; Liao, Y.; Nie, X.; Huang, B.; Wu, X.; Xie, Z. Assessing urban flood and drought risks under climate change, China. Hydrol. Process. 2019, 33, 1349-1361. [CrossRef]

5. Sun, Y.; Cheng, Q.-G.; Li, Y.; Fu, J. Assessment of eco-economic system sustainable development of Liaoning province based on emergy analysis. Ying Yong Sheng Tai Xue Bao J. Appl. Ecol. 2014, 25, 188-194.

6. Yang, W.; Zhao, J.; Zhao, K. Analysis of Regional Difference and Spatial Influencing Factors of Human Settlement Ecological Environment in China. Sustainability 2018, 10, 1520. [CrossRef]

7. Ye, Y.P.; Li, L.J. A Preliminary Study on Assessment Indicator System of Provincial Eccr Environmental Quality in China. Res. Environ. Sci. 2000, 13, 33-36. [CrossRef]

8. Li, J.P.; Li, M.R.; Wang, J.N.; Li, J.J.; Su, W.W.; Huang, M.X. Global Environmental Issues and Human Wellbeing. Report on Global Environmental Competitiveness; Springer: Berlin/Heidelberg, Germany, 2014; pp. 3-21.

9. Library, W.E. National Bureau of Statistics of China. 2005. Available online: http:/ /www.stats.gov.cn/english/ (accessed on 12 May 2021).

10. Willis, K.S. Remote sensing change detection for ecological monitoring in United States protected areas. Biol. Conserv. 2015, 182, 233-242. [CrossRef]

11. Shi, L.N.; Zhao, X.D.; Han, F. Application and Development Prospect of Remote Sensing Technology in Environment Monitoring. Guizhou Agric. Sci. 2010, 38, 175-178.

12. Ochoa-Gaona, S.; Kampichler, C.; de Jong, B.; Hernández, S.; Geissen, V.; Huerta, E. A multi-criterion index for the evaluation of local tropical forest conditions in Mexico. For. Ecol. Manag. 2010, 260, 618-627. [CrossRef]

13. Sullivan, C.A.; Skeffington, M.S.; Gormally, M.J.; Finn, J.A. The ecological status of grasslands on lowland farmlands in western Ireland and implications for grassland classification and nature value assessment. Biol. Conserv. 2010, 143, 1529-1539. [CrossRef]

14. Gao, P.W.; Kasimu, A.; Zhao, Y.Y.; Lin, B.; Chai, J.P.; Ruzi, T. Evaluation of the Temporal and Spatial Changes of Eco-logical Quality in the Hami Oasis Based on RSEI. Sustainability 2020, 12, 7716. [CrossRef]

15. Gupta, K.; Kumar, P.; Pathan, S.; Sharma, K. Urban Neighborhood Green Index-A measure of green spaces in urban areas. Landsc. Urban Plan 2012, 105, 325-335. [CrossRef]

16. Xu, H.Q. Modification of normalised difference water index (MNDWI) to enhance open water features in remotely sensed imagery. Int. J. Remote Sens. 2006, 27, 3025-3033. [CrossRef]

17. Wen, X.L.; Ming, Y.L.; Gao, Y.G.; Hu, X.Y. Dynamic Monitoring and Analysis of Ecological Quality of Pingtan Com-prehensive Experimental Zone, a New Type of Sea Island City, Based on RSEI. Sustainability 2019, 12, 21. [CrossRef]

18. Wu, Y.J.; Zhao, X.; Yue, X.I.; Liu, H.; Chang, L.I. Comprehensive evaluation and spatial-temporal changes of eco-environmental quality based on MODIS in Tibet during 2006-2016. Acta Geogr. Sin. 2019, 74, 1438-1449.

19. Li, Y.; Zhang, Q.; Wang, L.; Liang, L. Regional environmental efficiency in China: An empirical analysis based on en-tropy weight method and non-parametric models. J. Clean. Prod. 2020, 276, 124147. [CrossRef]

20. Hang, X.; Li, Y.; Luo, X.; Xu, M.; Han, X. Assessing the Ecological Quality of Nanjing during Its Urbanization Process by Using Satellite, Meteorological, and Socioeconomic Data. J. Meteorol. Res. 2020, 34, 280-293. [CrossRef]

21. Narumalani, S.; Zhou, Y.C.; Jensen, J.R. Application of remote sensing and geographic information systems to the de-lineation and analysis of riparian buffer zones. Aquat. Bot. 1997, 58, 393-409. [CrossRef]

22. He, J.B.; Li, Y.R.; Mao, J.F.; Wang, Z.; Li, S.J.; Zhang, H.J. Review of River Ecosystem Health Evaluation Methods. Environ. Technol. 2018, 31, 71-75. 
23. Foody, G. Editorial: Ecological applications of remote sensing and GIS. Ecol. Inform. 2007, 2, 71-72. [CrossRef]

24. Wang, Z.; Zhang, M.; Wang, L.; Qin, W.; Ma, Y.; Gong, W.; Yu, L. Investigating the all-sky surface solar radiation and its influencing factors in the Yangtze River Basin in recent four decades. Atmos. Environ. 2020, 244, 117888. [CrossRef]

25. $\mathrm{Hu}, \mathrm{X}$; $\mathrm{Xu}, \mathrm{H}$. A new remote sensing index for assessing the spatial heterogeneity in urban ecological quality: A case from Fuzhou City, China. Ecol. Indic. 2018, 89, 11-21. [CrossRef]

26. Guha, S.; Govil, H.; Gill, N.; Dey, A. A long-term seasonal analysis on the relationship between LST and NDBI using Landsat data. Quat. Int. 2020, 575-576, 249-258. [CrossRef]

27. Soltanian, F.K.; Abbasi, M.; Bakhtyari, H.R.R. Flood monitoring using NDWI and MNDWI spectral indices: A case study of Aghqala flood-2019, Golestan province, Iran. ISPRS Int. Arch. Photogramm. Remote Sens. Spat. Inf. Sci. 2019, XLII-4/W18, 605-607. [CrossRef]

28. Zoraghi, N.; Amiri, M.; Talebi, G.; Zowghi, M. A fuzzy MCDM model with objective and subjective weights for evalu-ating service quality in hotel industries. J. Ind. Eng. Int. 2013, 9, 38. [CrossRef]

29. Li, N.; Wang, J.; Qin, F. The improvement of ecological environment index model RSEI. Arab. J. Geosci. 2020, 13, 11.

30. Liao, W.; Jiang, W. Evaluation of the Spatiotemporal Variations in the Eco-environmental Quality in China Based on the Remote Sensing Ecological Index. Remote Sens. 2020, 12, 2462. [CrossRef]

31. Li, X.; Long, D. An improvement in accuracy and spatiotemporal continuity of the MODIS precipitable water vapor product based on a data fusion approach. Remote Sens. Environ. 2020, 248, 111966. [CrossRef]

32. Shao, Z.; Ding, L.; Li, D.; Altan, O.; Huq, E.; Li, C. Exploring the Relationship between Urbanization and Ecological Environment Using Remote Sensing Images and Statistical Data: A Case Study in the Yangtze River Delta, China. Sustainability 2020, 12, 5620. [CrossRef]

33. Chen, W.X.; Chi, G.Q.; Li, J.F. Ecosystem Services and Their Driving Forces in the Middle Reaches of the Yangtze River Urban Agglomerations, China. Int. J. Environ. Res. Public Health 2020, 17, 3717. [CrossRef] [PubMed]

34. Chen, K.J.; Wen, C.H.; Luo, Y.C. Yangtze River Protection Law Opening a new chapter of mother river protection. China Environment News, 6 January 2021; p. 3.

35. Gao, J.; Yu, Z.; Wang, L.; Vejre, H. Suitability of regional development based on ecosystem service benefits and losses: A case study of the Yangtze River Delta urban agglomeration, China. Ecol. Indic. 2019, 107, 105579. [CrossRef]

36. Xiong, Y.; Xu, W.; Lu, N.; Huang, S.; Wu, C.; Wang, L.; Dai, F.; Kou, W. Assessment of spatial-temporal changes of ecological environment quality based on RSEI and GEE: A case study in Erhai Lake Basin, Yunnan province, China. Ecol. Indic. 2021, 125, 107518. [CrossRef]

37. Zhao, G.; Tian, P.; Mu, X.; Jiao, J.; Wang, F.; Gao, P. Quantifying the impact of climate variability and human activities on streamflow in the middle reaches of the Yellow River basin, China. J. Hydrol. 2014, 519, 387-398. [CrossRef]

38. Yang, B.; Chen, X.; Wang, Z.; Li, W.; Zhang, C.; Yao, X. Analyzing land use structure efficiency with carbon emissions: A case study in the Middle Reaches of the Yangtze River, China. J. Clean. Prod. 2020, 274, 123076. [CrossRef]

39. Liu, L.; Chen, X.; Chen, W.; Ye, X. Identifying the Impact of Landscape Pattern on Ecosystem Services in the Middle Reaches of the Yangtze River Urban Agglomerations, China. Int. J. Environ. Res. Public Health 2020, 17, 5063. [CrossRef] [PubMed]

40. Verbesselt, J.; Hyndman, R.; Newnham, G.; Culvenor, D. Detecting trend and seasonal changes in satellite image time series. Remote Sens. Environ. 2010, 114, 106-115. [CrossRef]

41. $\mathrm{Xu}, \mathrm{H}$. A new index for delineating built-up land features in satellite imagery. Int. J. Remote Sens. 2008, 29, 4269-4276. [CrossRef]

42. Weng, Q.; Lu, D.; Schubring, J. Estimation of land surface temperature-vegetation abundance relationship for urban heat island studies. Remote Sens. Environ. 2004, 89, 467-483. [CrossRef]

43. Mudbhatkal, A.; Raikar, R.V.; Venkatesh, B.; Mahesha, A. Impacts of Climate Change on Varied River-Flow Regimes of Southern India. J. Hydrol. Eng. 2017, 22, 05017017. [CrossRef]

44. Chang, Z.; Qin, F.; Han, Z.; Yan, L.U.; Yu, Y.Y. Dynamic Evaluation of Eco-environmental Quality in He'nan Province Based on RS and GIS. Bull. Soil Water Conserv. 2017, 37, 132-137.

45. Wang, X.; Cao, Y.; Zhong, X.; Gao, P. A New Method of Regional Eco-environmental Quality Assessment and Its Application. J. Environ. Qual. 2012, 41, 1393-1401. [CrossRef] [PubMed]

46. Hou, K.; Li, X.X.; Wang, J.J.; Zhang, J. Evaluating Ecological Vulnerability Using the GIS and Analytic Hierarchy Process (AHP) Method in Yan'an, China. Pol. J. Environ. Stud. 2016, 25, 599-605.

47. $\mathrm{Wu}, \mathrm{Z}$; Chen, Y. The maximizing deviation method for group multiple attribute decision making under linguistic environment. Fuzzy Sets Syst. 2007, 158, 1608-1617. [CrossRef]

48. Pomerol, J.C.; Barba-Romero, S. Multicriterion Decision in Management: Principles and Practice; International Series in Operations Research \& Management Science; Springer: New York, NY, USA, 2000.

49. Fox, W.P.; Spence, G.; Kitchen, R.; Powell, S. Using the entropy weighting scheme in military decision making. J. Déf. Model. Simul. Appl. Methodol. Technol. 2019, 17, 409-418. [CrossRef]

50. Wang, Y.R. Remote Sensing Dynamic Monitoring of Vegetation Ecological Water Based on Spatio-Temporal Image Data Fusion; Chengdu University of Technology: Chengdu, China, 2020.

51. Dai, X.; Wang, L.; Huang, C.; Fang, L.; Wang, S.; Wang, L. Spatio-temporal variations of ecosystem services in the urban agglomerations in the middle reaches of the Yangtze River, China. Ecol. Indic. 2020, 115, 106394. [CrossRef] 
52. Huang, L.; Wu, C.Q. 2018 Ecological and Environmental Performance and its Improving Strategies of the Yangtze River Economic Belt. Reform 2018, 7, 116-126.

53. Tang, J.X.; Zeng, F. The response intensity of ecological environment to urbanization in the Yangtze River Economic Zone Spatial and temporal evolution. J. Cent. South Univ. For. Technol. 2021, 15, 4.

54. 2006 Hubei Environmental Status Bulletin; MB1803251/2019-32446; Hubei Department of Ecology and Environment: Wuhan, China, 2007.

55. 2008 Hubei Environmental Status Bulletin; MB1803251/2019-32454; Hubei Department of Ecology and Environment: Wuhan, China, 2009.

56. Song, K.; Wang, Y.J.; Ling, Y. Monitoring of ecological environment changes in the Yangtze River Economic Belt (Jiangsu Province) from 1999 to 2020 and analysis of driving forces of human activities. Bull. Surv. Mapp. 2021, 2, 7-12.

57. 2020 Hunan Environmental Status Bulletin; Hunan Department of Ecology and Environment: Changsha, China, 2021.

58. 2020 Hubei Environmental Status Bulletin; MB1803251/2021-27997; Hubei Department of Ecology and Environment: Wuhan, China, 2021. 